\title{
Texture and microstructure evolution in nickel electrodeposited from an additive-free Watts electrolyte
}

Alimadadi, Hossein; da Silva Fanta, Alice Bastos; Kasama, Takeshi; Somers, Marcel A. J.; Pantleon, Karen

Published in:

Surface and Coatings Technology

Link to article, DOI:

10.1016/j.surfcoat.2016.04.068

Publication date:

2016

Document Version

Peer reviewed version

Link back to DTU Orbit

Citation (APA):

Alimadadi, H., da Silva Fanta, A. B., Kasama, T., Somers, M. A. J., \& Pantleon, K. (2016). Texture and microstructure evolution in nickel electrodeposited from an additive-free Watts electrolyte. Surface and Coatings Technology, 299, 1-6. https://doi.org/10.1016/j.surfcoat.2016.04.068

\section{General rights}

Copyright and moral rights for the publications made accessible in the public portal are retained by the authors and/or other copyright owners and it is a condition of accessing publications that users recognise and abide by the legal requirements associated with these rights.

- Users may download and print one copy of any publication from the public portal for the purpose of private study or research.

- You may not further distribute the material or use it for any profit-making activity or commercial gain

- You may freely distribute the URL identifying the publication in the public portal 


\section{Accepted Manuscript}

Texture and microstructure evolution in nickel electrodeposited from an additive-free Watts electrolyte

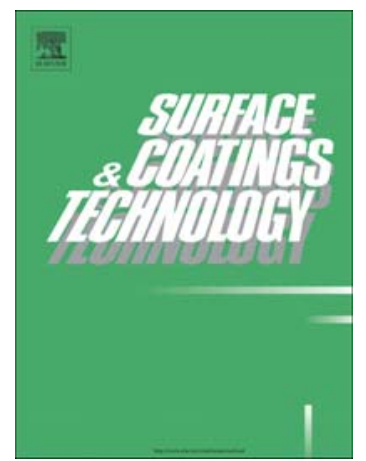

Hossein Alimadadi, Alice Bastos Fanta, Takeshi Kasama, Marcel A.J. Somers, Karen Pantleon

PII:

S0257-8972(16)30353-X

DOI: doi: 10.1016/j.surfcoat.2016.04.068

Reference: SCT 21143

To appear in: $\quad$ Surface \& Coatings Technology

Received date: 4 December 2015

Revised date: $\quad 26$ April 2016

Accepted date: $\quad 28$ April 2016

Please cite this article as: Hossein Alimadadi, Alice Bastos Fanta, Takeshi Kasama, Marcel A.J. Somers, Karen Pantleon, Texture and microstructure evolution in nickel electrodeposited from an additive-free Watts electrolyte, Surface \& Coatings Technology (2016), doi: 10.1016/j.surfcoat.2016.04.068

This is a PDF file of an unedited manuscript that has been accepted for publication. As a service to our customers we are providing this early version of the manuscript. The manuscript will undergo copyediting, typesetting, and review of the resulting proof before it is published in its final form. Please note that during the production process errors may be discovered which could affect the content, and all legal disclaimers that apply to the journal pertain. 
Texture and microstructure evolution in nickel electrodeposited from an additivefree Watts electrolyte

Hossein Alimadadi ${ }^{1,}{ }^{\dagger}$, Alice Bastos Fanta $^{1}$, Takeshi Kasama ${ }^{1}$, Marcel A.J. Somers ${ }^{2}$, Karen Pantleon $^{2}$

${ }^{1}$ Technical University of Denmark, Center for Electron Nanoscopy, Fysikvej, building 307, DK 2800 Kongens Lyngby, Denmark.

${ }^{2}$ Technical University of Denmark, Department of Mechanical Engineering, Produktionstorvet, building 425, DK - 2800 Kongens Lyngby, Denmark

† Corresponding Author, E-Mail: hoal@cen.dtu.dk, Tel.: +45 45256468 
Abstract: Nickel layers with $\langle 100\rangle,\langle 210\rangle,\langle 110\rangle$ and $\langle 211\rangle$ fiber textures were electrodeposited from additive-free Watts type electrolytes by adjusting both the $\mathrm{pH}$ and the applied current density. Quantitative crystallographic texture analysis by XRD was supplemented by microtexture analysis applying EBSD. While XRD results correspond to absorption-weighted averages over the top part of the layer, EBSD on the cross section allowed studying the texture evolution as a function of distance to the substrate. Although layer growth started on amorphous substrates, implying that nucleation occurs unbiased by the substrate, often relatively strong fiber textures develop already at the early stage of growth. These fiber textures can further develop into other preferred fiber axis further away from the substrate. The experimental results demonstrate that already in an early stage of deposition there are major differences in the developing textures. The evolution of the substrate-adjacent textures into the texture of thick layers depends strongly on the deposition conditions.

Keywords: Crystallographic texture, EBSD, Cross-section, Electrodeposition, Nickel, Watts electrolyte 


\section{Introduction}

Electrodeposition of nickel from Watts electrolyte [1] has been extensively used for decades and the influence of the electrodeposition parameters on microstructure and properties of the deposited nickel layers has been reported numerously. It has been shown that, for an additive-free Watts electrolyte, the following four major fiber textures can develop: $\langle 100\rangle,\langle 210\rangle,\langle 110\rangle$ and $\langle 211\rangle$ (where $\langle\mathrm{uvw}\rangle$ denotes the fiber axis), depending on the combination of $\mathrm{pH}$ and applied current density [2]. Each of these textures is associated with characteristic microstructural features, surface topography, and material properties [3-12]. Understanding the formation of different crystallographic textures facilitates the optimization of electrodeposition conditions for tailoring the internal structure. It has been argued that the evolution of preferred grain orientations during deposition is mainly influenced by the substrate and the electrodeposition parameters (i.e. bath composition, electric potential, current density, temperature, agitation, etc.) [13-16]. On the basis of TEM investigation of electrodeposited copper layers, it has been proposed that, approaching from the substrate/deposit interface to the deposit/electrolyte interface, the texture of the electrodeposit can be divided into three zones: $\mathrm{A}, \mathrm{B}$ and $\mathrm{C}$ [13]. In zone $\mathrm{A}$ the deposit is influenced by the substrate. For an amorphous substrate, no crystallographic influence can be exerted by the substrate, whereas a preferred orientation relation with the substrate can influence the texture of the deposit on a crystalline substrate. Zone B acts as a transition zone from zone A to C [13]. It has been proposed that zone B for an electrodeposit on an amorphous substrate is a mixture of randomly oriented grains and grains with an orientation similar to zone $\mathrm{C}$ [13]. The texture of zone $\mathrm{C}$ is mainly determined by the electrodeposition conditions. Various mechanisms have been proposed for explaining the texture of zone $\mathrm{C}$ [17]. For electrodeposition of nickel from an additive-free Wattstype electrolyte, the growth of certain crystallographic planes has been suggested to be inhibited (or promoted) by the adsorption of chemical species, and is generally accepted as the underlying 
mechanism for texture formation in zone $\mathrm{C}$ [16]. A $<210>$ fiber texture forms at low $\mathrm{pH}$ and high applied current density. This suggests that gaseous $\mathrm{H}_{2}$ favors the development of a $<210>$ fiber texture [16]. Based on the electrodeposition conditions under which $\langle 110\rangle$ and $\langle 211\rangle$ form, it has been proposed that adsorbed hydrogen, $\mathrm{H}_{\mathrm{ads}}$, and $\mathrm{Ni}(\mathrm{OH})_{2}$ are the chemical species that promote the evolution of $\langle 110\rangle$ and $\langle 211\rangle$ fiber textures, respectively [16]. The $\langle 100\rangle$ texture is considered the free mode of growth which forms when no chemical species inhibit the electrocrystallization process and the metallic surface is dynamically released from adsorbents [16].

The crystallographic texture of electrodeposits has been mainly studied by X-ray diffraction (XRD) analysis. This analysis technique averages over a surface of few $\mathrm{mm}^{2}$ with depth range of several micrometers. This can either be an advantage or a disadvantage. The advantage is that an average is obtained over a relatively large surface area. The major disadvantage is that an investigation of the depth-resolved evolution of the texture requires either a series of samples or destructive sublayer removal. The analysis of grain-orientation distributions in cross sections of electrodeposits by electron backscatter diffraction (EBSD) is an alternative technique to study the evolution of texture in the growth direction of an electrodeposit and simultaneously provides morphological information. The drawback of this technique is the relatively small surface area over which grain orientations are probed and the necessity of a high-quality, deformation-free cross sectional preparation. In the present work the four possible fiber textures evolving during electrodeposition from an additive-free Watts nickel electrolyte are investigated with cross sectional EBSD and supplemented with XRD analysis and transmission electron microscopy (TEM).

\section{Experimental}

\subsection{Materials}


Nickel electrodeposits were obtained from an additive-free Watts bath of composition $300 \mathrm{~g} \mathrm{dm}^{-3}$ $\mathrm{NiSO}_{4} \cdot 7 \mathrm{H}_{2} \mathrm{O}, 35 \mathrm{~g} \mathrm{dm}^{-3} \mathrm{NiCl}_{2} \cdot 6 \mathrm{H}_{2} \mathrm{O}$, and $40 \mathrm{~g} \mathrm{dm}^{-3} \mathrm{H}_{3} \mathrm{BO}_{3}$. To avoid the crystallographic texture bias of the electrodeposit by substrate, a copper sheet $\left(5 \times 6 \mathrm{~cm}^{2}\right.$ in size $)$ coated with an X-ray amorphous Ni-P film served as substrate. Ni-P layer was deposited from a commercially available electrolyte, NIPOSIT ${ }^{\mathrm{TM}} 65 \mathrm{R}$, for $80 \mathrm{~min}(\approx 10 \mu \mathrm{m}$ in thickness). Ni-P auto-catalytic (electroless) deposition was achieved at relatively high temperature of $365 \mathrm{~K}$. Immediately after Ni-P deposition, the copper piece coated with Ni-P layer was cleaned with distilled water and immersed in the nickel electrodeposition electrolyte. The electrolyte temperature for nickel electrodeposition was kept at $323 \mathrm{~K}$ and the electrolyte was vigorously stirred using a rotating magnet during the deposition. The $\mathrm{pH}$ and applied current density for electrodeposition were varied to bring about different growth textures (Table 1). To reduce or augment the $\mathrm{pH}$, small quantities of $\mathrm{H}_{2} \mathrm{SO}_{4}$ and $\mathrm{NH}_{4} \mathrm{OH}$ were added to the electrolyte. Since the deposition rate depends strongly on the applied current density, the deposition time was chosen such that identical charge transfer was achieved for all samples (see Table 1). It is noted that the identical charge transfer does not bring equal thickness of the deposit layer due to (i) the difference in cathode efficiency and (ii) the difference in the thickness profile across the cathode. Although the thickness of the deposits at the analyzed cross-section varies (see Table 1), in all the samples the layers were sufficiently thick to secure that the determined results of XRD texture analysis actually correspond to the texture dictated by the electrodeposition conditions, i.e. not covering the substrate-near region.

Table 1: The electrodeposition conditions: applied current density, $\mathrm{pH}$ and time used for the various samples Suvw (uvw refers to the anticipated $\langle u v w\rangle$ texture). Bath composition, agitation and deposition temperature were identical for all samples. The sample thickness at the analyzed area using electron microscopy is listed too. 


\begin{tabular}{|c|c|c|c|c|}
\hline Sample name & S100 & S210 & S110 & S211 \\
\hline Applied current density & 5 & 10 & 0.2 & 2 \\
{$\left[\mathrm{~A} \mathrm{dm}^{-2}\right]$} & 4.5 & 2.0 & 3.25 & 4.5 \\
\hline $\mathrm{pH}$ & 30 & 15 & 750 & 75 \\
\hline Deposition time [min] & 21 & 19 & 24 & 21 \\
\hline Thickness $[\mu \mathrm{m}]$ & & & & \\
\hline
\end{tabular}

\subsection{X-ray diffraction texture analysis}

The nickel electrodeposits were investigated with XRD for quantitative crystallographic texture analysis. A Bruker AXS D8 Discover X-ray diffractometer equipped with an Eulerian cradle was used and operated with $\mathrm{Cu}-\mathrm{K} \alpha$ radiation. For quantitative texture analysis, pole figures of 111, 200 and 220 reflections were measured, applying sample rotation around the surface normal (azimuth angle $\varphi, 0 \leq \varphi \leq 360^{\circ}$, step size $5^{\circ}$ ) and sample tilts (pole angle $\psi, 0 \leq \psi \leq 75^{\circ}$, step size $5^{\circ}$ ). Measured intensities were corrected for background intensity and a Ni-powder standard was used to correct for defocusing, associated with tilting. Following [18], the complete 3D orientation distribution function was calculated.

\subsection{Sample preparation for microscopy}

The samples were prepared as cross-sections by mechanical polishing with a final step of $0.04 \mu \mathrm{m}$ colloidal silica (OP-S, Struers). To ensure removal of the deformed layer originating from mechanical polishing, samples were further prepared by FIB milling with $\mathrm{Ga}^{+}$ions at $30 \mathrm{keV}$ in two steps. Firstly, about $700 \mathrm{~nm}$ were removed by applying an ion beam current of $2.8 \mathrm{nA}$ (rough milling). Subsequently, an additional $50 \mathrm{~nm}$ were removed by milling with a current of $0.46 \mathrm{nA}$ 
(gentle milling). This preparation was optimized for the present samples, such that no artifacts are introduced into the cross sections to be investigated.

For transmission electron microscopy, an electron transparent lamella specimen was prepared in an FEI Helios Nanolab ${ }^{\mathrm{TM}} 600$ dual beam microscope, using an in-situ lift-out technique [19], in which $30 \mathrm{kV} \mathrm{Ga}^{+}$were used to the penultimate step. For the final step (removal of amorphous layer), $2 \mathrm{kV}$ $\mathrm{Ga}^{+}$with the current of $30 \mathrm{pA}$ was applied with an incident angle of $7^{\circ}$, for both sides of the lamella for $10 \mathrm{~min}$. The prepared lamella covers the whole thickness of the deposit and contains the growth direction within the plane of the lamella.

\subsection{EBSD}

EBSD measurements were carried out in an FEI Helios Nanolab ${ }^{\mathrm{TM}} 600$ dual beam equipped with an EBSD system from EDAX-TSL and a Hikari camera. The measurements were performed with an electron probe current of $5.5 \mathrm{nA}$ at an acceleration voltage of $12 \mathrm{kV}$, with step size of $25 \mathrm{~nm}$. The OIM $5^{\mathrm{TM}}$ software was used for analysis of the EBSD results. Post-acquisition treatment was applied in the following steps. Firstly, the clean-up routine Confidence Index (CI) standardization was applied. In this routine the highest CI value of a point within a grain was assigned to all other points belonging to the same grain. A grain was defined as a region consisting of at least three connected points with misorientations less than $5^{\circ}$. Thereafter, grain dilation was applied. For this cleaning procedure, the orientation of a point which does not belong to any grain was considered to correspond to the orientation of the majority of neighboring points belonging to one and the same grain. Finally, all the data points with $\mathrm{CI}<0.1$ were disregarded.

For micro-texture analysis of the EBSD data the OIM $5^{\mathrm{TM}}$ software was applied. The position of the interface between substrate and electrodeposit is not obvious from the EBSD maps, because the grain size in the deposit close to this interface is smaller than the currently achievable resolution of 
technique [20]. The position of substrate/deposit interface was therefore defined as follows. The CI value of the as-measured data (prior to cleaning) was averaged for all the points along lines at the same distance from the bottom of the map. The position of the interface was defined as the location where the thus averaged CI-value exceeds 0.1 , i.e. the certainty of correct indexing was higher than 95\% [21]. By means of example, the averaged CI-value versus distance from the bottom of the map for sample S211 is shown in Fig. 1. Analogously, the position of the outer surface of the deposit was defined as the location where the average CI-value reaches a value below 0.1 .

To characterize the microstructure evolution in the growth direction, sub-maps were taken at intervals of $2 \mu \mathrm{m}$ along the growth direction. The texture within each sub-map was assessed using a harmonic series expansion to the rank of 22 , with a Gaussian half width of $3^{\circ}$.

\subsection{Transmission electron microscopy}

TEM investigations were carried out at $200 \mathrm{kV}$ on the prepared lamella using an FEI Tecnai T20. Ni-P substrate and nickel electrodeposit layer adjacent to the substrate were characterized using bright-field imaging and selected area electron diffraction.

\section{Results}

\section{Texture evolution}

For the analysis of $\mathrm{XRD}$ texture results, the complete $3 \mathrm{D}$ orientation distribution function was calculated. Since the samples have a fiber texture with fiber axis parallel to the growth direction (GD) of the layer, the inverse pole figure (IPF) in GD fully characterizes the texture in the deposit. All XRD texture results are shown in Figs 2a-d. Sample S100 (Fig. 2a) has a major <100> fiber texture and a minor <111> fiber component. For sample S210 (Fig. 2b), the major texture component is $\langle 210\rangle$. In addition, two minor components close to $\langle 542\rangle$ and $\langle 711\rangle$ are also 
identified. Samples S110 (Fig. 2c) and S211 (Fig. 2d) show single components of <110> and $<211>$, respectively. Orientation maps of the four samples as evaluated from EBSD data are presented in Fig. 3. The corresponding micro-textures are given in Figs $2 \mathrm{f}-\mathrm{i}$. A very good agreement is observed between the XRD texture (Figs 2a-d) and the EBSD texture results (Figs 2f-i).

The evolution of texture in GD is characterized by dividing the EBSD map of each sample into smaller portions, each covering $2 \mu \mathrm{m}$ in GD (cf. Fig. 4). For sample S100, which develops a <100> texture at the later stages of growth, the texture in the first $2 \mu \mathrm{m}$ is of mixed character (a weak $<511>$ component and a contribution of <111>). Ranging from $2-8 \mu \mathrm{m}$ from the interface, the texture is close to $\langle 100\rangle$, with an intensity maximum at $\langle\mathrm{X} 11\rangle$ (with $\mathrm{X}$ between 5 and 8 ). For sample S210, the texture is weak close to the deposit/substrate interface. At a distance of $4 \mu \mathrm{m}$ from the interface, the texture remains weak, although various components evolve. Further away from the interface a major $\langle 210\rangle$ has developed, accompanied by two minor components, $\langle 542\rangle$ and $<711\rangle$, both originating from twinning of $\langle 210\rangle$ [22]. This texture remains on further growth of the electrodeposit. Sample S110 has a very strong <100> texture at an early stage of growth $(0-2 \mu \mathrm{m}$ layer from the interface), but this changes significantly at 2-4 $\mu \mathrm{m}$ from the deposit/substrate interface. In the growth direction, a $\langle 110\rangle$ texture evolves with distance to the interface, and becomes strongest at the surface. Similarly, also for S211 in the first few microns a $<100>$ texture is present, albeit weaker than for S110 and now accompanied by <211>. Beyond $2 \mu \mathrm{m}$, the $<211>$ texture is the only remaining component and its strength increases with distance to the interface.

For all the samples, the texture evolves with increasing distance from the substrate interface by changes of both the type and the strength(s) of the fiber texture component(s) compared to the nearsubstrate region. The distance from the substrate from where the texture remains unchanged and governs the overall fiber texture is different for the four samples. For sample S100 this is observed 
in the range 8-10 $\mu \mathrm{m}$ from the interface; for sample S110 at $14-16 \mu \mathrm{m}$, for sample $\mathrm{S} 211$ at 2-4 $\mu \mathrm{m}$ and for sample S210 at 4-6 $\mu \mathrm{m}$.

\section{Microstructure evolution}

As mentioned above, the interface between Ni-P substrate and electrodeposit cannot be characterized using EBSD. Hence, TEM with superior resolution to EBSD is applied to characterize the early stage of growth. As shown by means of example for sample S210 in Figs 5a and d, nickel grains of few tens of nanometer in size, from on the Ni-P substrate. The selected area electron diffraction pattern (Fig. 5b) of an area of the deposit close to the substrate shows a typical pattern of randomly oriented FCC crystals. Additionally, selected area electron diffraction pattern of the substrate shown in Fig. 5c, reveals that Ni-P is a significantly disordered, low crystalline phase, hence, cannot bias the electrodeposition.

The orientation maps in Fig. 3 show remarkable differences for the various deposition conditions. For S100 (Fig. 3a) and S211 (Fig. 3b), for which only the applied current densities during deposition was different, a major difference in the microstructure is the occurrence of grain boundaries. For S211 grain and twin boundaries are more or less parallel to the growth direction, while for S100 the twins are inclined with respect to the growth direction (see in this respect also Ref. 12, where ion channeling images of these microstructures were presented). Reducing the applied current density to a very low change transfer (i.e. growth) rate, while simultaneously reducing the $\mathrm{pH}$, leads to the microstructure $\mathrm{S} 110$ in Fig. 3c. A peculiar feature is the abrupt change from $<100>$ oriented grains adjacent to the nanocrystalline zone A, to a gradually reinforcing $<110>$ texture. This microstructure does not reflect growth selection within the first $10 \mu \mathrm{m}$ as for the other microstructures, but rather is the result of repeated nucleation. In addition, several grains are inclined with respect to the growth direction; very few grains reaching the surface can actually 
be traced back to the zone with the $\langle 100\rangle$ texture. Finally, the microstructure developing at the highest charge transfer rate is S210 in Fig. 3b. Here the columns are internally twinned in such a way that 5-fold grain junctions develop in the cross section (see also [22]).

\section{Discussion}

The electrodeposition conditions applied in this study were chosen such that four major fiber textures evolved (cf. Fig. 2). A comparison of the XRD-measured texture, shown in Figs 2a-d, which represents an average over a volume of several $\mathrm{mm}^{3}$, with micro-texture analysis by EBSD in Figs $2 \mathrm{f}-\mathrm{i}$, which represent an average over a volume of about $20 \mu \mathrm{m} \times 20 \mu \mathrm{m} \times 20 \mathrm{~nm}$, shows a very good agreement between the two techniques. Thus, the texture analysis by EBSD is representative for the microstructure, despite the considerably smaller volume analyzed and the associated poorer crystal statistics for texture assessment as compared to the XRD analysis.

XRD analysis is traditionally used for the texture determination in Watts-bath nickel electrodeposits. If the deposit is relatively thick, thin transition zones of $\sim 2 \mu \mathrm{m}$ for samples S211 and S100 and $\sim 4 \mu \mathrm{m}$ for S210 can be overlooked, as seen in the present study for XRD texture in the mentioned samples, cf. Fig. 2. Cross-sectional characterization of deposits using EBSD has previously been applied on various materials $[29,30]$ including nickel $[4,22,28]$. However, microtexture information [31] is rarely obtained. For the investigations that EBSD micro-texture is obtained [32], the investigation of the various stages of deposition is not carried out. This is despite the importance of different texture components on the properties of electrodeposits [33, 34].

Sample S110 has a very strong $<100>$ fiber in the first $2 \mu \mathrm{m}$ from the interface, but changes to a $<110>$ towards the sample surface. For sample S100, close to the interface, a double fiber texture with <111> and <511> fibers parallel to the growth direction is present, but disappears while a $<100>$ texture develops. For samples S211 the final fiber texture component is already present in 
the substrate-adjacent region together with a $\langle 100\rangle$, which vanishes while the strength of $\langle 211\rangle$ increases. Similarly, sample S210 already contains a $<210>$ fiber texture in the substrate-adjacent region. The observed texture evolutions clearly indicate that the three zone model [13] is too simplistic to accurately describe the evolution of the growth texture in nickel electrodeposited from an additive-free Watts electrolyte. The main shortcoming of this model concerns the transition zone (B), where a weaker fiber texture is predicted than in zone C. Based on the current results it is evident that the transition zone between the substrate-controlled zone A and the electrodepositioncontrolled zone $\mathrm{C}$, depends strongly on the electrodeposition conditions and the growth mode developed in the early stage, perhaps even in the nanocrystalline layer. The transition zone becomes of particular practical importance for relatively thin deposits.

It is not possible on the basis of the present results to provide a full explanation for the developing microstructures and textures, because essential information on the inhibiting (or promoting) effects of species developing during electrodeposition and adsorbing at the advancing deposite/electrolyte interface are inaccessible. Regardless of this fact, based on the results provided above, inhibition of chemical species has shortcomings for explaining the experimentally observed transition zone texture, especially for sample S100 where a <111> fiber component is present at the early stage of growth. Based on inhibition of chemical species, formation of $<111>$ fiber requires a very strong inhibition [16]. In the case of Watts nickel, <111> fiber texture cannot be achieved unless organic chemical compounds such as 2-butyne-1,4-diol are added into the electrolyte [12,16,35]. Thus, it is highly unlikely that any chemical species present in the additive-free Watts electrolyte at any stage of growth be able to exert <111> texture. Additionally, due to the very small grain size forming on the Ni-P substrate (see Figs 5a and d), the actual surface area at the very early stage of growth is 
very high ${ }^{1}$, and as the deposit grows the interfacial area decreases. Hence, inhibition intensity increases as the deposit grows. Accordingly, if inhibition mechanism is solely concerned, for sample S100, at early stage of growth where inhibition intensity is low, <111> forms (which requires very high inhibition) and at later stages free mode of growth $<100>$ prevails. This is contradictory and one can conclude that mechanism(s) other than inhibition should also play a role in the texture formation of the transition zone.

It is well-known that the energy minimization of nanocrystalline materials brings about formation of different texture components [25]. When the inherent nanocrystalline nature of the deposit is concerned, minimization of strain and/or interfacial energy contributions eventually results in the evolution of $\langle 100\rangle$ fiber or $<111>$ fiber [25]. Including the influence of grain size provides a better explanation/speculation on possible mechanisms playing a role in texture development as provided below.

At the very early stage of growth (zone A), as shown in Figs $5 \mathrm{a}$ and d, the size of grains neighboring the Ni-P substrate is below the physical resolution of EBSD at the applied experimental conditions, i.e. $\sim 30 \mathrm{~nm} \times 90 \mathrm{~nm} \times 10 \mathrm{~nm}$ [20]. In agreement with literature, an amorphous substrate (see the selected-area diffraction pattern of Ni-P substrate Fig. 5c) is anticipated not to exert a crystallographic bias on the nucleating electrodeposit [13, 23, 24] and randomly oriented nickel crystallites should develop, irrespective of the electrodeposition conditions (Fig. 5b). Accordingly, as compared to later stages of electrodeposition, an inhibiting effect of adsorbed species (developing) in the electrolyte requires a large concentration of these species in relation to the total amount of deposited nickel. If the concentration of inhibiting species at the cathode surface is sufficiently high, the strength of fiber texture will gradually increase into that imposed by the

\footnotetext{
${ }^{1}$ Assuming (i) square base pyramid grains with height and base edge length of $20 \mathrm{~nm}$ and (ii) cathode of $5 \times 5$ $\mathrm{cm}^{2}$, the actual surface area is $\sim 1.4 \times 10^{13}$ times larger than the nominal area of $25 \mathrm{~cm}^{2}$.
} 
deposition conditions (i.e. zone C). An example is observed for sample S210. On the other hand, if the concentration of inhibiting species at the cathode surface is low, the inherent nanocrystalline nature of the deposit determines the developing texture in zone B. For relatively fine grains, the balance between the reduction of $\operatorname{strain}^{2}$ and interfacial energies (the combination of grain boundary energy and surface energy) governs the growth rate of different grain orientations. Then, the outcome of this energy balance in competition with the charge transfer rate, i.e. the nickel deposition rate governs the evolving texture. For dominance of strain energy minimization, the $<100>$ fiber develops, as for samples S110 and S211. For dominance of interfacial energy minimization, the $<111>$ fiber develops, as observed in sample S100.

For $\mathrm{S} 100$ the $<111>$ fiber in the transition zone is accompanied by its twin counterpart, the <511> fiber. A similar texture evolution has been reported for the electrodeposition of a copper oxide [26]. For low to medium stacking-fault-energy FCC metals twinning has been demonstrated to bring about a change in texture during electrodeposition [27]. The occurrence of twinning is the consequence of favorable nucleation of new crystals on dense packed planes. The twin counterpart of a $<100>$ fiber, i.e. $<221>$ fiber, was not experimentally observed in this study nor in a similar experiment for nickel sulfamate electrolyte with $<110>$ texture (see Fig. 2 in [28]).

Eventually, the grains grow in size, and hence, strain and surface energy minimization become of less importance. Moreover, the actual surface area of the cathode decreases, and finally, inhibition by adsorption of (developing) species in the electrolyte can become more effective and zone $\mathrm{C}$ evolves.

\section{Summary and Conclusions}

\footnotetext{
${ }^{2}$ The combination of defects within the grains such as vacancies and self-interstitials and inter-crystalline features such as triple lines.
} 
Nickel layers with $\langle 100\rangle,\langle 210\rangle,\langle 110\rangle$ and $\langle 211\rangle$ fiber textures were electrodeposited onto amorphous Ni-P substrates from additive-free Watts type electrolytes by adjusting both the $\mathrm{pH}$ and the applied current density. The method for characterization of the micro-texture evolution of nickel deposits using cross-sectional EBSD measurement as presented in this work can in principle be applied to other systems with evolving texture.

It was demonstrated that the texture as determined with X-ray diffraction texture analysis over a relatively large volume gives similar results as texture analysis by EBSD in the depth range where the X-rays have probed the crystallites, thereby validating the determination of texture evolution as a function of distance to the substrate in a cross-section over the deposit.

It is pointed out that the transition zone from substrate controlled (zone A) to deposition controlled (zone C) growth, is strongly dependent on the conditions at the cathode surface. Further, it is speculated that if the concentration of inhibiting species present in the electrolyte, or developing from the electrolyte during deposition, is low, the nanocrystalline nature of the deposit dictates the texture. If interface energy minimization is dominant or strain energy minimization is dominant, textures with $\langle 111\rangle$ and $\langle 100\rangle$ fibers develop, respectively. Texture components can be accompanied by their twinning counterparts.

For Watts-nickel deposits, samples with $\langle 110\rangle$ and $\langle 211\rangle$ fiber textures in zone C, the transition zone is interpreted to be mainly controlled by strain-energy minimization. For samples with dominant $<210>$ and $<100>$ fiber textures respectively interfacial energy minimization and repeated twining are believed to govern the texture evolution.

\section{Acknowledgement}


The authors acknowledge the Danish Research Council for Technology and Production Sciences (Grant No. 274-07-0492) for financial support. The A.P. Møller and Chastine Mc-Kinney Møller Foundation is gratefully acknowledged for their contribution toward the establishment of the Center for Electron Nanoscopy in the Technical University of Denmark.

\section{References}

[1] O. P. Watts, Trans. Am. Electrochem. Soc. 29 (1916) 395-403.

[2] J. Amblard and M. Froment, Faraday Symp. Chem. Soc. 12 (1977) 136-144.

[3] J. Amblard, G. Maurin, D. Mercier, and N. Spyrellis, Scr. Metall. 16 (1982) 579-584.

[4] A. Shibata, H. Noda, M. Sone, and Y. Higo, Thin Solid Films 518 (2010) 5153-5158.

[5] K. Hashimoto, JAP INST Met. TRANS, 6 (1965) 166-171.

[6] E. J. Suoninen and T. Hakkarainen, J. Mater. Sci., 3 (1968) 446-448.

[7] V. Velinov, S. Vitkova, and N. Pangarov, Surf. Technol. 6 (1977) 19-29.

[8] G. Csiszár, K. Pantleon, H. Alimadadi, G. Ribárik, and T. Ungár, J. Appl. Crystallogr. 45 (2012) 6170.

[9] M. Motoyama, Y. Fukunaka, T. Sakka, and Y. H. Ogata, J. Electrochem. Soc., 153 (2006) C502.

[10] O. Devos, O. Aaboubi, J.-P. Chopart, E. Merienne, A. Olivier, and J. Amblard, J. Electrochem. Soc., 145 (1998) 4135-4139.

[11] R. Weil, Annu. Rev. Mater. Sci., 19 (1989) 165-182.

[12] H. Alimadadi, A. B. Fanta, M. A. J. Somers, and K. Pantleon, Surf. Coat. Technol. 254 (2014) 207216.

[13] A. A. Rasmussen, J. A. D. Jensen, A. Horsewell, and M. A. J. Somers, Electrochimica Acta, 47 (2001) 67-74.

[14] A. A. Rasmussen, P. Møller, and M. A. J. Somers, Surf. Coat. Technol. 200 (2006) 6037-6046.

[15] E. Gómez, R. Pollina, and E. Vallés, J. Electroanal. Chem. 386 (1995) 45-56.

[16] J. Amblard, I. Epelboin, M. Froment, and G. Maurin, J. Appl. Electrochem. 9 (1979)233-242.

[17] C. Nielsen, A. Horsewell, M. Østergård, J. Appl. Electrochem. 27 (1997) 839-845. 
[18] H. J. Bunge and P. R. Morris, Texture analysis in materials science: mathematical methods. Butterworths London;, 1982.

[19] M. Schaffer, B. Schaffer, Q. Ramasse, Ultramicroscopy, 114 (2012) 62-71.

[20] S. Zaefferer, Ultramicroscopy, 107 (2007) 254-266.

[21] D. P. Field, Ultramicroscopy, 67 (1997) 1-9.

[22] H. Alimadadi, A. Bastos Fanta, M. A. Somers, and K. Pantleon, Appl. Phys. Lett.103 (2013) 031918031918.

[23] F. Ebrahimi and Z. Ahmed, Mater. Charact. 49 (2002) 373-379.

[24] T. Watanabe, Nano Plating - Microstructure Formation Theory of Plated Films and a Database of Plated Films. Elsevier Science, 2004.

[25] C. V. Thompson and R. Carel, J. Mech. Phys. Solids, 44 (1996) 657-673.

[26] J. A. Switzer, H. M. Kothari, and E. W. Bohannan, J. Phys. Chem. B, 106 (2002) 4027-4031.

[27] T. H. V. Setty and H. Wilman, Trans. Faraday Soc. 51(1955) 984-995.

[28] S. Pathak, M. Guinard, M. G. C. Vernooij, B. Cousin, Z. Wang, J. Michler, and L. Philippe, Surf. Coat. Technol. 205 (2011) 3651-3657.

[29] A. Bastos, S. Zaefferer, D. Raabe, and C. Schuh, Acta Mater.54 (2006) 2451-2462.

[30] T. Liu, D. Raabe, W. Mao, and S. Zaefferer, Adv. Funct. Mater. 19 (2009) 3880-3891.

[31] D. J. Dingley and V. Randle, J. Mater. Sci. 27 (1992) 4545-4566.

[32] T. Buchheit, J. Michael, T. Christenson, D. LaVan, and S. Leith, Metall. Mater. Trans. A, 33 (2002) 539-554.

[33] C. L. P. Pavithra, B. V. Sarada, K. V. Rajulapati, M. Ramakrishna, R. C. Gundakaram, T. N. Rao, and G. Sundararajan, Cryst. Growth Des. 15 (2015): 4448-4458.

[34] A. Godon, J. Creus, S. Cohendoz, E. Conforto, X. Feaugas, P. Girault, and C. Savall, Scr. Mater. 62 (2010) 403-406.

[35] C. Gábor, K. Pantleon, H. Alimadadi, G. Ribárik, and T. Ungár, Journal of Applied Crystallography 45, (2012) 61-70. 
Figure captions:

Figure 1: average confidence (CI) index vs distance from bottom of the measured EBSD data map for sample S211.

Figure 2: The inverse pole figure (IPF) in growth direction (GD) obtained by XRD measurements for sample (a) S100, (b) S210, (c) S110, and (d) S211. (e) The iso-density levels of XRD texture data. The micro-texture represented by inverse pole figure (IPF) in growth direction (GD) for sample (f) S100, (g) S210, (h) S110, and (i) S211 based on the EBSD data. The corresponding orientation maps are shown in Figure 3. (j) The contour levels of EBSD micro-texture data.

Figure 3: Orientation map, color coded in relation with the electrodeposit's growth direction (GD) shown by an arrow in the legend; high angle grain boundaries are shown in black; (a) S100, (b) S210, (c) S110, and (d) S211.

Figure 4: The IPF in growth direction (GD) for sub-maps made each $2 \mu \mathrm{m}$; covering from substrate/deposit interface to the surface of deposit.

Figure 5: (a) Bright-field TEM image of sample S210 showing the Ni-P substrate and nickel electrodeposit fine grains formed at the very early stage of growth. (b) and (c) Selected-area electron diffraction pattern of the nickel layer and Ni-P substrate, acquired from the regions marked on (a) with circles. (d) Higher magnification bright-field image of the same sample. 


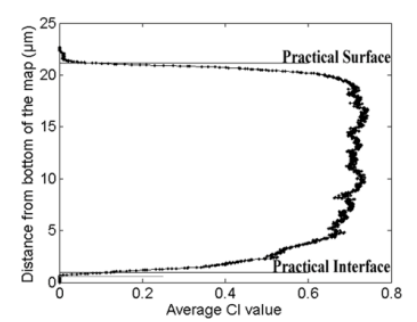

Figure 1 

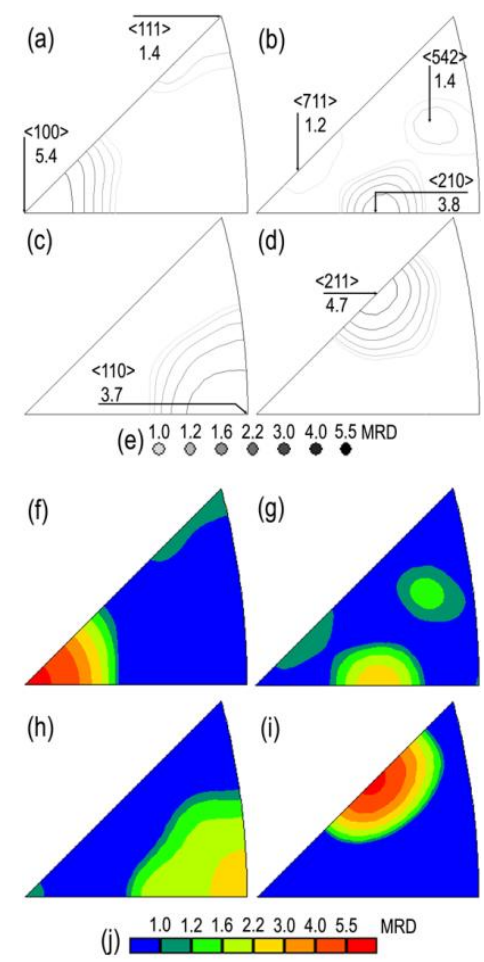

Figure 2 


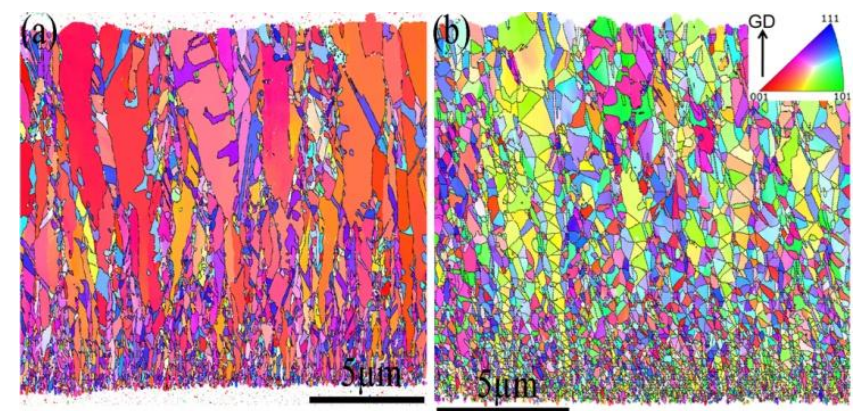

(c)

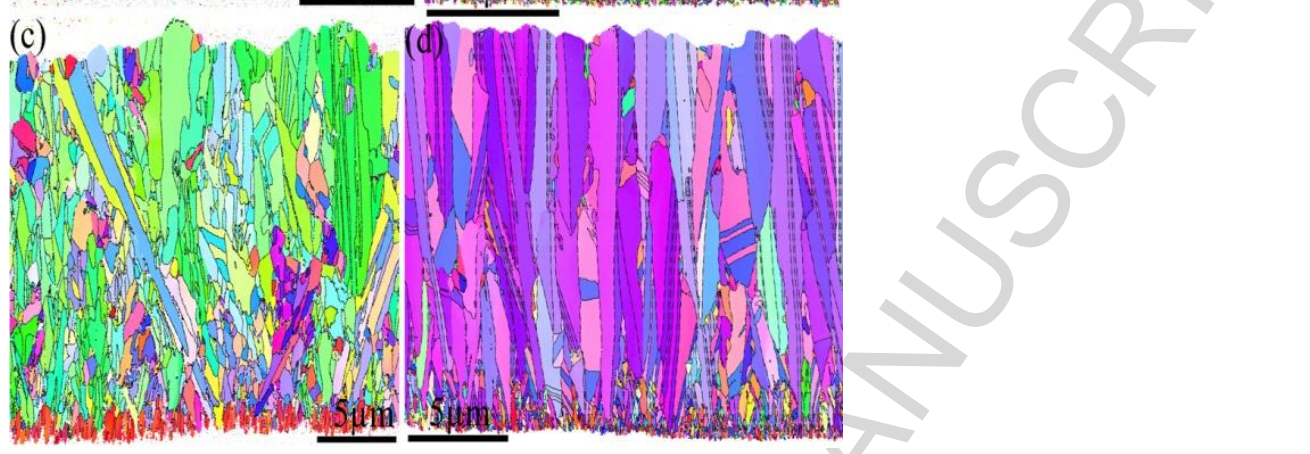

Figure 3 


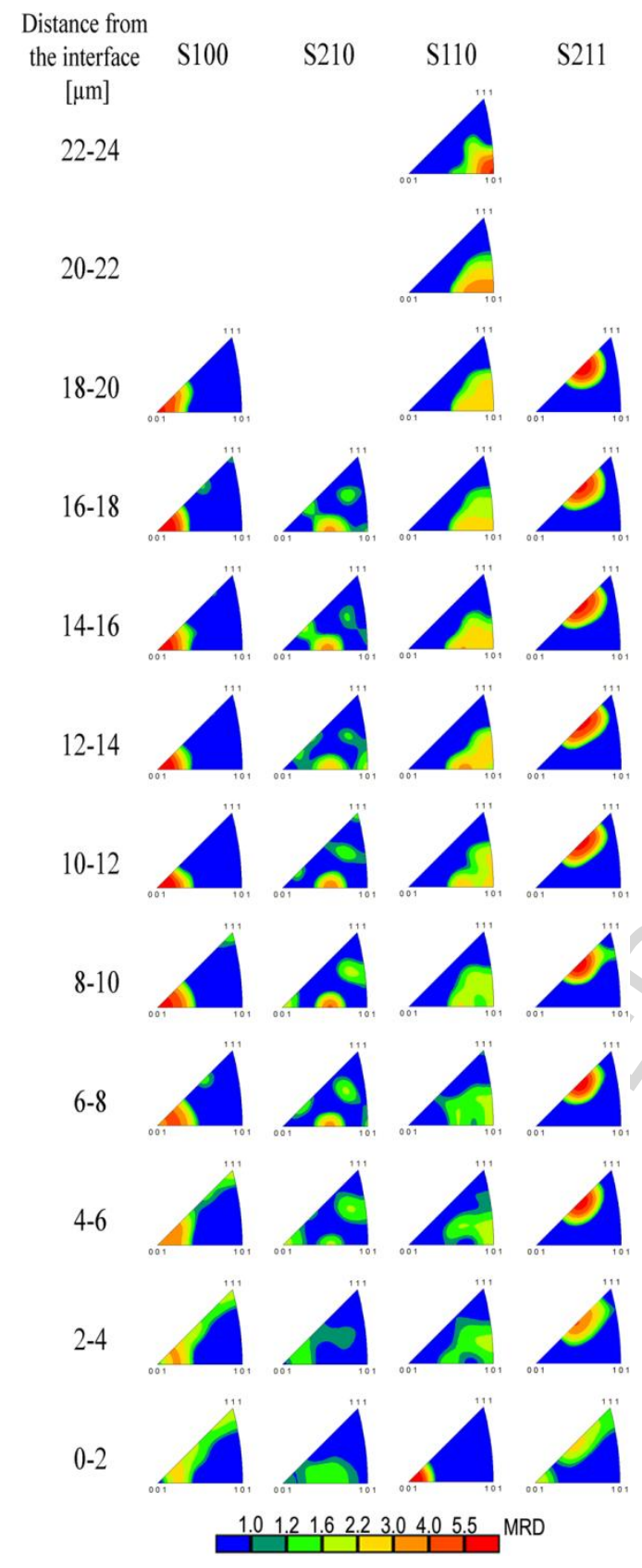

Figure 4 

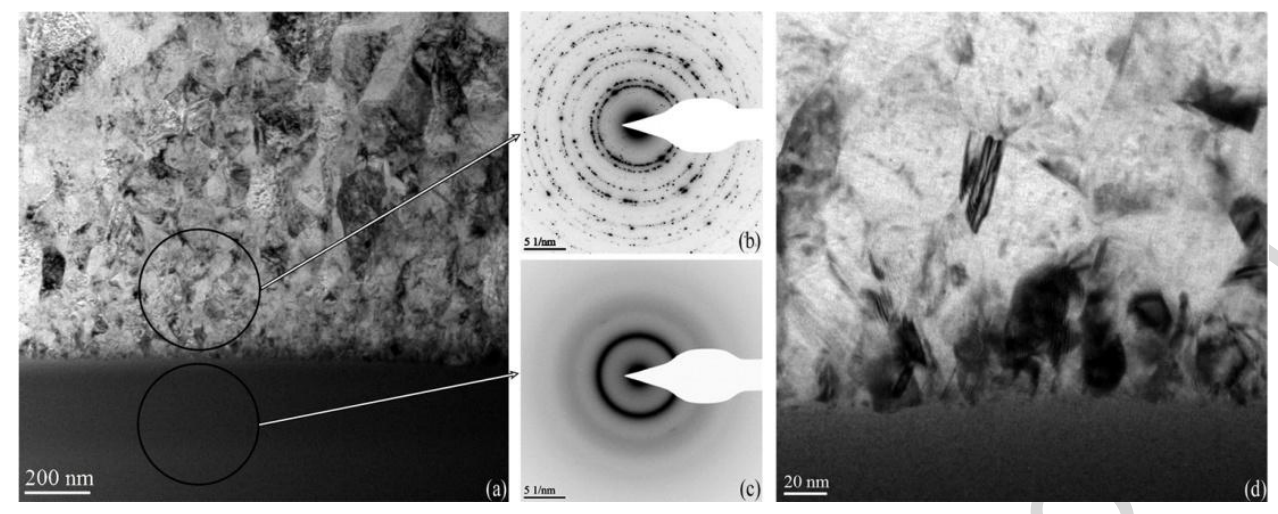

Figure 5 
Table 1: The electrodeposition conditions: applied current density, $\mathrm{pH}$ and time used for the various samples Suvw (uvw refers to the anticipated $\langle u v w\rangle$ texture). Bath composition, agitation and deposition temperature were identical for all samples. The sample thickness at the analyzed area using electron microscopy is listed too.

\begin{tabular}{|c|c|c|c|c|}
\hline Sample name & S100 & S210 & S110 & S211 \\
\hline Applied current density & & & & \\
{$\left[\mathrm{A} \mathrm{dm}^{-2}\right]$} & 5 & 10 & 0.2 & 2 \\
\hline $\mathrm{pH}$ & 4.5 & 2.0 & 3.25 & 4.5 \\
\hline Deposition time $[\mathrm{min}]$ & 30 & 15 & 750 & 75 \\
\hline Thickness $[\mu \mathrm{m}]$ & 21 & 19 & 24 & 21 \\
\hline
\end{tabular}




\section{Highlights}

Journal: Surface and Coatings Technology

Title: Texture and microstructure evolution in nickel electrodeposited from an additive-free Watts electrolyte

- Nickel layers with $\langle 100\rangle,\langle 210\rangle,\langle 110\rangle$ and $\langle 211\rangle$ fiber textures were electrodeposited.

- Microtexture evolution of nickel deposits using cross-sectional EBSD is applied.

- It is shown that transition zone from substrate controlled to deposition controlled growth, is strongly dependent on the conditions at the cathode surface.

- It is pointed out that if inhibition intensity at the cathode surface is not sufficiently high the texture of transition zone is dictated by interface energy or strain energy minimization of nanocrystals. 